\title{
Hospital utilisation among people born in refugee-source countries: an analysis of hospital admissions, Victoria, 1998-2004
}

\author{
Ignacio Correa-Velez, Vijaya Sundararajan, Kaye Brown and Sandra M Gifford
}

A

ustralia is one of 16 nations that resettle refugees under the United Nations

High Commissioner for Refugees program, ${ }^{1}$ and has the second largest intake in proportion to its population, accepting about 13000 humanitarian entrants annually. ${ }^{2}$ All humanitarian visa holders have immediate access to Medicare, Australia's publicly funded universal health care scheme.

Variations in patterns of hospital utilisation among migrant populations have been documented in a number of countries. ${ }^{3-6}$ These studies have shown that, overall, immigrants do not have higher rates of hospital utilisation compared with those born in the country of hospitalisation. However, there is a dearth of research on the use of health services by people from refugee backgrounds who have resettled in industrialised nations. This lack of evidence is of particular significance, not only because of the vulnerability and disadvantage of refugee populations, ${ }^{7,8}$ but also because of the need to inform policies and services that aim to improve the health of these communities.

We analysed a 6-year statewide hospital discharge dataset to investigate whether inequalities in hospital use and health outcomes exist among people born in refugeesource countries compared with the Australian-born population in Victoria.

\section{METHODS}

\section{Admissions data source}

The Victorian Admitted Episodes Dataset (VAED) was used to analyse hospital admissions for the 6 financial years from 1 July 1998 to 30 June 2004. The VAED contains morbidity data on all patients admitted to public and private hospitals in Victoria. Clinical data are stored as ICD-10-AM ${ }^{9}$ (International classification of diseases, 10th revision, Australian modification) codes in 25 diagnosis and procedures fields for 1998-99 to 2002-03, increasing to 40 fields in 2003-04. Permission to use de-identified data was obtained from the Victorian Department of Human Services.

\section{Refugee-source countries}

Two major shortcomings of the VAED are a lack of data on immigration status and a

\section{ABSTRACT}

Objective: To investigate whether hospital utilisation and health outcomes in Victoria differ between people born in refugee-source countries and those born in Australia.

Design and setting: Analysis of a statewide hospital discharge dataset for the 6 financial years from 1 July 1998 to 30 June 2004. Hospital admissions of people born in eight countries for which the majority of entrants to Australia arrived as refugees were included in the analysis.

Main outcome measures: Age-standardised rates and rate ratios for: total hospital admissions; emergency admissions; surgical admissions; total days in hospital; discharge at own risk; hospital deaths; admissions due to infectious and parasitic diseases; and admissions due to mental and behavioural disorders.

Results: In 2003-04, compared with the Australia-born Victorian population, people born in refugee-source countries had lower rates of surgical admission (rate ratio [RR], $0.85 ; 95 \% \mathrm{Cl}, 0.81-0.88)$, total days in hospital (RR, $0.74 ; 95 \% \mathrm{Cl}, 0.73-0.75)$, and admission due to mental and behavioural disorders (RR, 0.70; $95 \% \mathrm{Cl}, 0.65-0.76)$. Over the 6-year period, rates of total days in hospital and rates of admission due to mental and behavioural disorders for people born in refugee-source countries increased towards Australian-born averages, while rates of total admissions, emergency admissions, and admissions due to infectious and parasitic diseases increased above the Australian-born averages.

Conclusions: Use of hospital services among people born in refugee-source countries is not higher than that of the Australian-born population and shows a trend towards Australian-born averages. Our findings indicate that the Refugee and Humanitarian Program does not currently place a burden on the Australian hospital system.

MJA 2007; 186: 577-580

lack of indicators for ethnicity (with the exception of Indigenous status) beyond country of birth of the patient. Hence, we used country of birth as a proxy indicator of refugee status. Refugee-source countries are defined as those countries where significant numbers of people have been forcibly displaced due to persecution, violence, and war. ${ }^{8}$ Here, we focus on the eight source countries from which most entrants to Victoria from 1980 onwards arrived under the Refugee and Humanitarian Program; this cut-off date was chosen to differentiate entrants from recent refugee-source countries from those from former refugee-source countries who have entered more recently under the family and general migration programs (eg, Vietnamese and Cambodians). ${ }^{2,10}$ The recent refugee-source countries included are Afghanistan, BosniaHerzegovina, Burma, Eritrea, Ethiopia, Iraq, Somalia and Sudan. Data for recent refugee arrival numbers were obtained from the Australian Government Depart- ment of Immigration and Multicultural Affairs Settlement Database. ${ }^{2}$

\section{Admission rates}

Hospital admission rates were age-standardised using the direct method. ${ }^{11}$ As Victorian population estimates by country of birth and age category were not readily available from the Australian Bureau of Statistics for all individual refugee-source countries, population figures for people born in these countries were estimated by adding the number of arrivals to Victoria born in each country $^{2}$ to the number of individuals recorded at the previous census as being born in each country. ${ }^{12}$ Figures from the 1996 and 2001 censuses were used to estimate the Australian-born population. ${ }^{12}$ The estimated resident population of Victoria was used as the standard population.

A random sample of 100000 admissions of Australian-born people was taken for each year and compared with the total number of admissions for people 


\begin{tabular}{|lrrr}
\hline \multirow{2}{*}{$\begin{array}{l}\text { Estimated population in Victoria, and number of arrivals and proportion of } \\
\text { humanitarian arrivals in Victoria, by refugee-source country of birth }\end{array}$} \\
\cline { 3 - 4 } $\begin{array}{l}\text { Refugee-source } \\
\text { country of birth }\end{array}$ & $\begin{array}{r}\text { Estimated population } \\
\text { in Victoria (2004)* }\end{array}$ & No. of arrivals in Victoria (1996-2004) & $\begin{array}{c}\text { Proportion arriving on } \\
\text { humanitarian visas }\end{array}$ \\
\cline { 3 - 4 } Afghanistan & 4061 & 2743 & $87.1 \%$ \\
Bosnia-Herzegovina & 8861 & 2043 & $92.4 \%$ \\
Burma & 1295 & 304 & $68.8 \%$ \\
Eritrea & 1190 & 552 & $69.4 \%$ \\
Ethiopia & 2796 & 1639 & $59.2 \%$ \\
Iraq & 7701 & 4163 & $81.7 \%$ \\
Somalia & 2685 & 1525 & $77.4 \%$ \\
Sudan & 3740 & 3544 & $97.5 \%$ \\
Total & 32329 & 16513 & $79.2 \%$ \\
\hline
\end{tabular}

* Data sources: 1996 and 2001 censuses $^{12}$ and Settlement Database. ${ }^{2}+$ Data source: Settlement Database. ${ }^{2}$.

\section{Total hospital admissions by refugee-source country of birth and financial year of analysis, Victoria, 1998-99 to 2003-04}

\begin{tabular}{lcccccc}
$\begin{array}{l}\text { Refugee-source } \\
\text { country of birth }\end{array}$ & $\mathbf{1 9 9 8 - 9 9}$ & $\mathbf{1 9 9 9 - 2 0 0 0}$ & $\mathbf{2 0 0 0 - 0 1}$ & $\mathbf{2 0 0 1 - 0 2}$ & $\mathbf{2 0 0 2 - 0 3}$ & 2003-04 \\
\hline Afghanistan & 600 & 650 & 834 & 1142 & 1312 & 1440 \\
Bosnia-Herzegovina & 1062 & 1450 & 2310 & 2641 & 3298 & 3266 \\
Burma & 298 & 348 & 491 & 547 & 550 & 675 \\
Eritrea & 337 & 345 & 414 & 404 & 528 & 497 \\
Ethiopia & 458 & 553 & 639 & 736 & 1021 & 1206 \\
Iraq & 1313 & 1556 & 1778 & 1884 & 2350 & 2835 \\
Somalia & 794 & 863 & 860 & 1127 & 1117 & 1266 \\
Sudan & 121 & 172 & 192 & 300 & 477 & 778 \\
Total & 4983 & 5937 & 7518 & 8781 & 10653 & 11963
\end{tabular}

born in refugee-source countries in the same year. Rate ratios are used to illustrate these comparisons. ${ }^{11}$ The Australian-born population was used as the reference group, so a rate ratio greater than 1.00 indicates that admissions were higher for people born in refugee-source countries than for Australian-born people. Admission rates and rate ratios are presented with $95 \%$ confidence levels. Confidence intervals for age-adjusted rates were calculated with the method based on the $\gamma$ distribution. ${ }^{13}$

The following indicators were assessed for people born in refugee-source countries and compared with those born in Australia over the 6-year period:

- total hospital admissions;

- emergency admissions;

- surgical admissions;

- total days in hospital;

- discharge at own risk;
- hospital deaths;

- admissions due to infectious and parasitic diseases (ICD-10-AM ${ }^{9}$ codes A00-A99 and B00-B99); and
- admissions due to mental and behavioural disorders (F00-F99 codes $^{9}$ ).

A conservative approach was used in comparing rate ratios for refugee-sourcecountry-born and Australian-born populations. When confidence intervals of rate ratios for people born in refugee-source countries overlapped with those of the Australian-born population, rate ratios were defined as similar. Rate ratios for people born in refugee-source countries were defined as higher or lower than for the Australian-born population if they were higher or lower in at least 4 of the 6 years analysed.

Data were analysed using SAS, version 8.2 (SAS Institute Inc, Cary, NC, USA).

\section{RESULTS}

Our estimates indicate that about $80 \%$ of arrivals in Victoria from the eight refugeesource countries between 1996 and 2004 entered Australia under the humanitarian program (Box 1). A total of 49835 hospital admissions of people born in these countries were recorded between 1998-99 and 200304 (Box 2).

Box 3 compares age-standardised rates between people born in refugee-source countries and Australian-born people for the last year of analysis (2003-04). People born in refugee-source countries had statistically significantly $(P<0.05)$ higher rates of total hospital admissions and emergency admissions, and lower rates of surgical admissions, total days in hospital, and admissions due to mental and behavioural disorders.

Rates for all outcomes increased between 1998-99 and 2003-04 for both Australianborn people and people born in refugeesource countries (except for infectious/para-

\begin{tabular}{|c|c|c|}
\hline \multicolumn{3}{|c|}{$\begin{array}{l}3 \text { Comparison of age-standardised hospital admission rates (per } 1000 \text { persons) } \\
(95 \% \mathrm{Cl}) \text { between people born in refugee-source countries and Australian- } \\
\text { born people, Victoria, 2003-04 }\end{array}$} \\
\hline Outcome & Born in a refugee-source country & Born in Australia \\
\hline Total hospital admissions & $495.2(484.7-505.9)$ & $444.8(442.0-447.6)$ \\
\hline Emergency admissions & $113.2(108.2-118.4)$ & $100.9(99.6-102.2)$ \\
\hline Surgical admissions & 96.7 (92.4-101.3) & $114.3(112.9-115.7)$ \\
\hline Total days in hospital & 1102.7 (1085.9-1119.8) & $1493.2(1488.0-1498.4)$ \\
\hline Discharge at own risk & $1.7(1.1-2.4)$ & $1.1(0.9-1.2)$ \\
\hline Hospital deaths & $4.1(3.1-5.5)$ & $4.4(4.1-4.7)$ \\
\hline $\begin{array}{l}\text { Admissions due to } \\
\text { infectious/parasitic diseases }\end{array}$ & $22.4(20.3-24.6)$ & $20.3(19.7-20.9)$ \\
\hline $\begin{array}{l}\text { Admissions due to } \\
\text { mental/behavioural disorders }\end{array}$ & $24.0(21.9-26.4)$ & $34.2(33.5-35.0)$ \\
\hline
\end{tabular}




\section{Rate ratios and $95 \% \mathrm{Cls}^{*}$ for outcomes assessed - people born in refugee-source countries compared with Australian-born people, ${ }^{\dagger}$ 1998-99 to 2003-04}
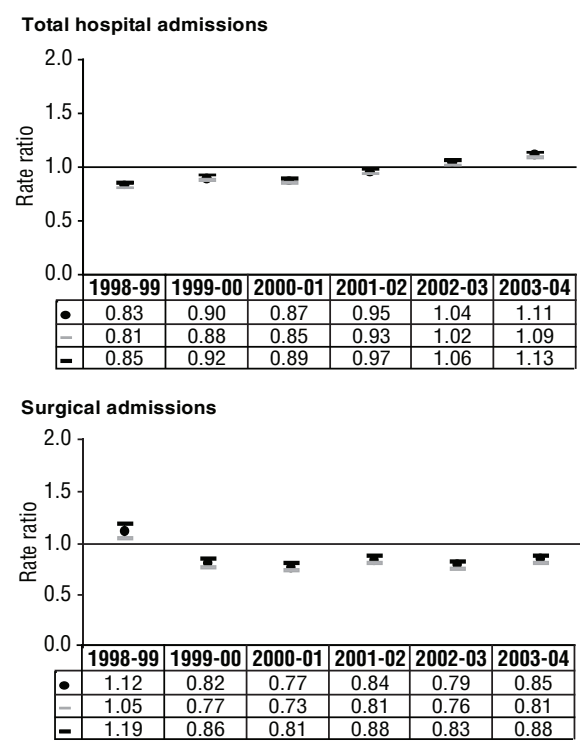

Discharge at own risk

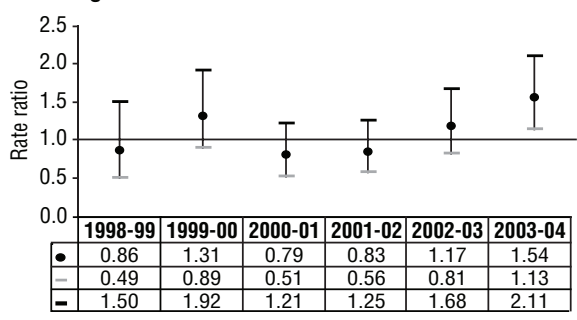

Infectious/parasitic diseases admissions
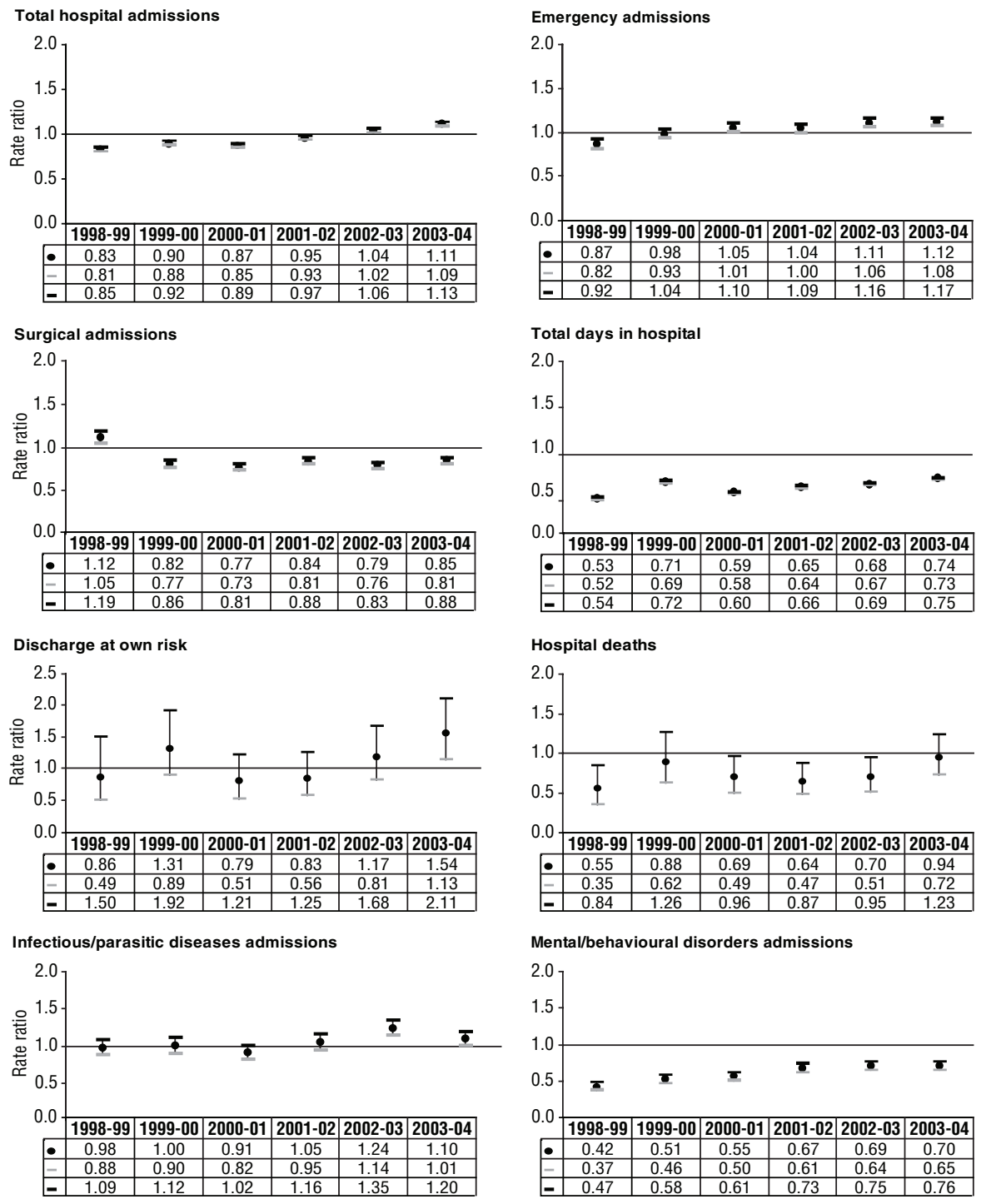

* Circles represent rate ratios, with corresponding figures shown in the first line of each table. Bars represent lower and upper $95 \% \mathrm{Cls}$, with corresponding figures shown in the second and third lines of each table, respectively. $†$ Reference group $=$ Australian-born people (rate ratio, 1.00). findings agree with a number of other studies that have compared hospital utilisation between immigrants and those born in the country of hospitalisation, which also found that, overall, immigrants have lower ${ }^{3,14}$ or similar $^{6,15}$ rates of hospital utilisation. The few previous studies that have compared refugees with people born in the country of hospitalisation have involved small samples drawn from individual hospitals. ${ }^{16,17}$ These studies reported no significant differences in hospitalisation rates.

A key strength of our study, when compared with self-reported health surveys, ${ }^{14,15}$ is the use of a hospital discharge dataset that provides objective characteristics of health care utilisation. To our knowledge, this is the first study that has used a statewide hospital discharge database to compare, over a considerable period of time, hospital admissions between people born in refugeesource countries and those born in the country of hospitalisation. A study of hospital discharges conducted in Canada ${ }^{4}$ used broader birthplace categories, without focusing specifically on refugee-source countries, and found that only those born in the Middle East and Central and West Africa recorded higher hospitalisation rates in the first year of arrival than the Canadian-born population.

Our study was not able to clarify whether low levels of use reflect reduced levels of need or unidentified barriers to hospital utilisation. The health screening process that refugee applicants must undergo before entering Australia ${ }^{18}$ may be filtering out those with poor health, thereby reflecting a "healthy refugee" effect. ${ }^{7}$ There is, however, increasing evidence of poorer health status and high prevalence of a range of health problems among recently arrived refugees in Australia. ${ }^{19-21}$

Although there is some evidence of the multiple barriers that prevent refugees from adequately accessing health care services, much of the existing research is based on small samples or on anecdotal data provided by health care workers. ${ }^{22,23}$ One way to measure whether people born in refugeesource countries face difficulties in accessing hospitals would be to assess utilisation rates by length of time in Australia. It can be argued that recent arrivals would have less knowledge about the availability of hospital services than those who had been in the country longer. Unfortunately, length of time in Australia was not available in the hospital dataset used here. Nevertheless, the increases seen in admission rates among 
people born in refugee-source countries over the 6-year period may indicate that the use of hospital services among this population increased the longer they were in Australia, as they became more familiar with the health system and the availability of services. Alternatively, it might be that admission rates increased due to poorer health status and specific health care needs of those arriving in Victoria over the last 2-3 years of our analysis.

Our study has a number of limitations. First, as we used de-identified admissions data from a cross-sectional hospital dataset, the unit of measurement is an episode of hospitalisation rather than an individual patient. Nevertheless, de-identified hospital admissions data can be a helpful indicator of the disease burden to populations and health services. ${ }^{24}$ Second, our findings are influenced by the quality of ICD-10-AM coding in the hospital dataset. However, a recent study assessing the quality of this dataset found high levels of reliability and adherence to coding standards. ${ }^{25}$ Third, the lack of information on immigration status prevented the analysis of those arriving exclusively on refugee visas. However, most arrivals born in the countries selected have entered Australia under the humanitarian program. ${ }^{2,10}$ Fourth, studying all refugee-source-country groups together may mask differences among specific subgroups. However, using a broad definition of refugee-source countries makes our findings more generalisable than if a single group had been compared with the Australian-born population. ${ }^{26}$

In conclusion, we found that the use of hospital services among people born in refugee-source countries is no higher than that of people born in Australia, and shows a trend towards Australian-born averages. Our findings indicate that the Refugee and Humanitarian Program does not currently place a burden on the Australian hospital system.

\section{ACKNOWLEDGEMENTS}

This study was funded by the Refugee Health Research Centre, La Trobe University. In-kind support was provided by the Chronic Disease Surveillance and Epidemiology Section, Rural and Regional Health and Aged Care Services, Victorian Department of Human Services. We thank Dr Michael Ackland and the staff from the Chronic Disease Surveillance and Epidemiology Section. The VAED data were supplied by the Victorian Department of Human Services. Any views expressed here are our own and not those of the Department.
Ignacio Correa-Velez is supported by a National Health and Medical Research Council (NHMRC) Public Health (Australia) Fellowship (Grant No. 380845).

\section{COMPETING INTERESTS}

None identified.

\section{AUTHOR DETAILS}

Ignacio Correa-Velez, MD, PhD, NHMRC Postdoctoral Research Fellow and Deputy Director $^{1}$

Vijaya Sundararajan, MD, MPH, Senior Epidemiologist ${ }^{2}$

Kaye Brown, PhD, Project Officer ${ }^{2}$

Sandra M Gifford, MPH, PhD, Director and Professor $^{1}$

1 Refugee Health Research Centre, Faculty of Health Sciences, La Trobe University, Melbourne, VIC.

2 Chronic Disease Surveillance and Epidemiology Section, Victorian Department of Human Services, Melbourne, VIC.

\section{Correspondence:}

i.correa-velez@latrobe.edu.au

\section{REFERENCES}

1 United Nations High Commissioner for Refugees. The state of the world's refugees: human displacement in the new millennium. New York: Oxford University Press, 2006.

2 Department of Immigration and Multicultural Affairs. Settlement Database. Canberra: DIMA, 2005.

3 Kliewer EV, Butler JRG. Hospital morbidity patterns and costs of immigrants in Australia. Canberra: National Centre for Epidemiology and Population Health, Australian National University, 1995.

4 Kliewer E, Kazanjian A. The health status and medical services utilization of recent immigrants to Manitoba and British Columbia: a pilot study. Vancouver: British Columbia Office of Health Technology Assessment, 2000.

5 Berg JE, Johnsen E. [Are immigrants admitted to emergency psychiatric departments more often than ethnic Norwegians?] [Norwegian]. Tidsskr Nor Laegeforen 2004; 124: 634-636.

6 Laroche M. Health status and health services utilization of Canada's immigrant and nonimmigrant populations. Can Public Policy 2000; 26: $51-75$

7 Beiser $M$. The health of immigrants and refugees in Canada. Can J Public Health 2005; 96 Suppl 2: S30-S44.

8 Thomas SL, Thomas SD. Displacement and health. Br Med Bull 2004; 69: 115-127.

9 National Centre for Classification in Health. Australian coding standards. International statistical classification of diseases and related health problems, 10th revision. Australian modification (ICD-10-AM). Vol 5. 2nd ed. Sydney: $\mathrm{NCCH}, 2000$.

10 Jupp J, editor. The Australian people. An encyclopedia of the nation, its people and their origins. Melbourne: Cambridge University Press, 2001.
11 Kirkwood BR, Sterne JAC. Essential medical statistics. 2nd ed. Malden, Mass: Blackwell Science, 2003.

12 Australian Bureau of Statistics. Census of population and housing, 1996 and 2001. Number of persons by sex, by age, by birthplace of individual, by area of usual residence (Victoria and Australia). Canberra: ABS, 2005.

13 Fay MP, Feuer EJ. Confidence intervals for directly standardized rates: a method based on the gamma distribution. Stat Med 1997; 16: 791-801.

14 Chen J, Ng E, Wilkins R. The health of Canada's immigrants in 1994-95. Health Rep 1996; 7: 3345.

15 Dunn JR, Dyck I. Social determinants of health in Canada's immigrant populations: results from the National Population Health Survey. Soc Sci Med 2000; 51: 1573-1593.

16 Olsen B. [Refugee or immigrant children in hospital] [Norwegian]. Tidsskr Nor Laegeforen 1998; 118: 3585-3588.

17 Blochliger C, Osterwalder J, Hatz C, et al [Asylum seekers and refugees in the emergency department] [German]. Soz Praventivmed 1998; 43: 39-48.

18 Department of Immigration and Multicultural Affairs. Health requirement for permanent entry to Australia. Form 1071i. Canberra: DIMA, 2006. http://www.immi.gov.au/allforms/pdf/ 1071i.pdf (accessed Apr 2007).

19 Bureau of Immigration, Multicultural and Population Research. Immigration update March quarter 1996: recent immigrants' health and wellbeing, results from the BIMPR longitudinal survey. Canberra: BIMPR, 1996.

20 Tiong ACD, Patel MS, Gardiner J, et al. Health issues in newly arrived African refugees attending general practice clinics in Melbourne. Med $J$ Aust 2006; 185: 602-606.

21 Martin JA, Mak DB. Changing faces: a review of infectious disease screening of refugees by the Migrant Health Unit, Western Australia in 2003 and 2004. Med J Aust 2006; 185: 607-610.

22 Sheikh-Mohammed M, Maclntyre CR, Wood $\mathrm{NJ}$, et al. Barriers to access to health care for newly resettled sub-Saharan refugees in Australia. Med J Aust 2006; 185: 594-597.

23 Atwell R, Correa-Velez I, Gifford S. A profile of Victorian seniors from refugee backgrounds: health and wellbeing needs and access to aged care health and support services. Melbourne: Refugee Health Research Centre, La Trobe University, 2005

24 Metcalfe C, Thompson SG, Cowie MR, Sharples LD. The use of hospital admission data as a measure of outcome in clinical studies of heart failure. Eur Heart J 2003; 24: 105-112.

25 Henderson T, Shepheard J, Sundararajan V. Quality of diagnosis and procedure coding in ICD-10 administrative data. Med Care 2006; 44: 1011-1019.

26 Blais R, Maiga A. Do ethnic groups use health services like the majority of the population? A study from Quebec, Canada. Soc Sci Med 1999; 48: 1237-1245.

(Received 9 Nov 2006, accepted 8 Feb 2007) 